\title{
Avaliações de conforto ambiental e eficiência energética do projeto do prédio do Centro de Informações do Cresesb, no Rio de Janeiro
}

\author{
Evaluation of environmental comfort and energy \\ efficiency of the building design of the Information \\ Center of Cresesb, Rio de Janeiro
}

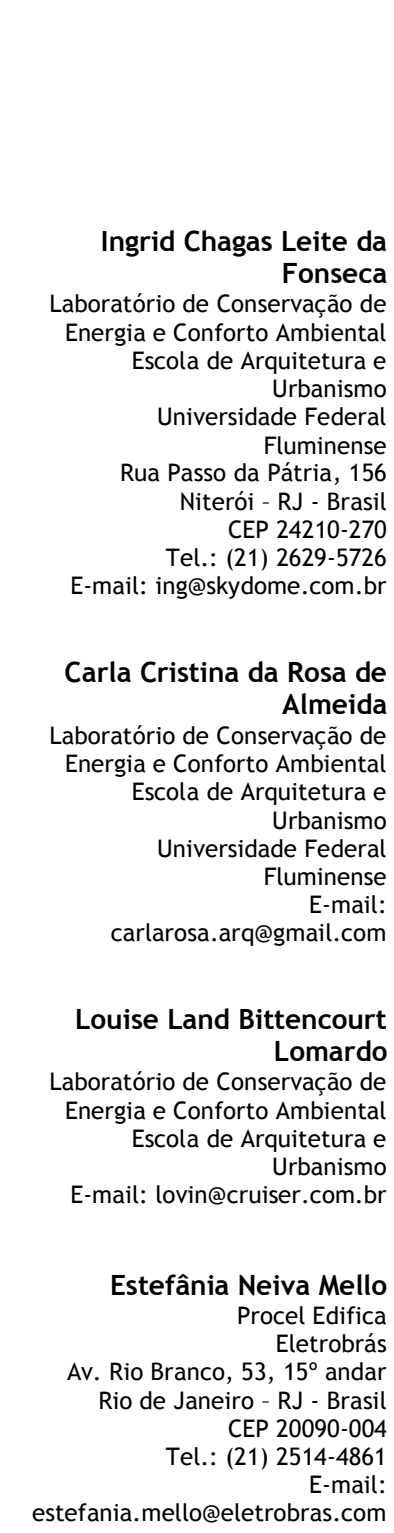

Recebido em 20/02/2010 Aceito em 02/06/2010

\section{Ingrid Chagas Leite da Fonseca \\ Carla Cristina da Rosa de Almeida \\ Louise Land Bittencourt Lomardo \\ Estefânia Neiva Mello}

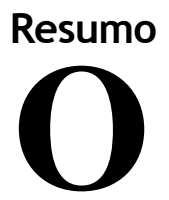

artigo apresenta avaliações de conforto ambiental e eficiência energética do projeto do prédio do Centro de Informações do Centro de Referência para as Energias Solar e Eólica Sérgio de Salvo Brito (Cresesb), a ser construído na Ilha do Fundão, no Rio de Janeiro, realizadas pela equipe do Laboratório de Conservação de Energia e Conforto Ambiental (LabCECA), da Universidade Federal Fluminense (UFF). O projeto do edifício levou em consideração os princípios da arquitetura bioclimática, com aproveitamento racional dos recursos passivos para a obtenção de conforto ambiental. Inicialmente, são descritos os princípios gerais para a obtenção de conforto ambiental em clima tropical quente e úmido. Na sequiência, são apresentadas as características do projeto de arquitetura do prédio, que privilegiou o aproveitamento dos recursos naturais. O Regulamento Técnico da Qualidade do Nível de Eficiência Energética de Edifícios Comerciais, de Serviços e Públicos, RTQ-C, pelo método prescritivo, foi aplicado no projeto do edifício, e seus resultados comprovam a eficiência energética desse projeto bioclimático.

Palavras-chave: Arquitetura bioclimática. Conforto ambiental. Eficiência energética. RTQ-C.

\section{Abstract}

This paper presents evaluations of the environmental comfort and energy efficiency of the building design of the Information Center of CRESESB Reference Center for Solar and Wind Energy Sérgio de Salvo Brito - to be built at Ilha do Fundão, Rio de Janeiro, conducted by the Laboratory of Energy Conservation and Environmental Comfort of Fluminense Federal University $(U F F)$. The building design took into account the principles of bioclimatic architecture, with efficient use of passive resources to obtain environmental comfort. Initially, the paper describes the general principles for achieving environmental comfort in a tropical, hot and humid climate. Then, the characteristics of the architectural design, which considered the use of natural resources as a priority, are presented. The Technical Regulation Quality Level of Energy Efficiency in Commercial and Public Buildings" (RTQ-C), by the prescriptive method, was applied for the building design and the results demonstrate the energy efficiency of this bioclimatic design.

Keywords: Bioclimatic architecture. Environmental comfort. Energy efficiency. RTQ-C. 


\section{Introdução}

O Centro de Referência para as Energias Solar e Eólica Sérgio de Salvo Brito (Cresesb) foi criado em 1994, na Ilha do Fundão, no Rio de Janeiro, com a missão de promover o desenvolvimento das energias solar e eólica mediante a difusão de conhecimentos, a ampliação do diálogo entre as entidades envolvidas e o estímulo à implementação de estudos e projetos.

O Cresesb faz parte do Centro de Pesquisas de Energia Elétrica do Sistema Eletrobrás (Cepel), e a construção de sua nova sede é uma de suas metas. A operação desse centro de informações visa promover com maior eficiência atividades de treinamento e de divulgação técnico-científica e, ao mesmo tempo, ampliar o efeito de demonstração já conseguido com a Casa Solar Eficiente, já construída no mesmo local, em seus oito anos de funcionamento.

O projeto, de autoria das arquitetas Estefânia Mello e Lana Carmona, orientado pela arquiteta Louise Lomardo e concebido com uso dos recursos bioclimáticos, tem o objetivo de ser um espaço aberto ao público, destinado a aplicar e a difundir tecnologias alternativas em energia, principalmente de fontes alternativas, e demonstrar a influência que a arquitetura exerce no uso da energia e, principalmente, na garantia do conforto higrotérmico, acústico, lumínico, e da qualidade do ar, empregando pouco insumo energético. Outros projetos com objetivos semelhantes foram construídos no Brasil, como a Casa Eficiente (MACIEL et al., 2006), e em outros países, como o Centro de Demonstração e Educação "Pacific Energy Center" da PG\&E” (c2009), por exemplo.

Nesse contexto, o projeto do Centro foi avaliado segundo o Regulamento Técnico da Qualidade do Nível de Eficiência Energética de Edifícios Comerciais, de Serviços e Públicos, o RTQ-C (BRASIL, 2009c), cujo objetivo é classificar o nível de eficiência energética de edifícios em três quesitos: envoltória, iluminação artificial e ar condicionado.

O quesito envoltória tem destaque neste artigo, visto que as estratégias bioclimáticas adotadas no projeto foram responsáveis pela classificação $\mathrm{A}$, segundo a metodologia adotada no RTQ-C (BRASIL, 2009c), o que confirma a importância do projeto arquitetônico bioclimático, que, aliado a materiais adequados e tecnologias apropriadas, pode aumentar os níveis de conforto e reduzir, em paralelo, os desperdícios de energia.

A avaliação foi realizada pela equipe do Laboratório de Conservação de Energia e Conforto Ambiental (LabCECA), da Universidade Federal
Fluminense (UFF), sob a coordenação da Professora Louise Land Bittencourt Lomardo.

Este artigo visa apresentar o estudo de caso de um edifício projetado a partir das premissas bioclimáticas para o clima quente e úmido da cidade do Rio de Janeiro e a aplicação da metodologia de avaliação de eficiência energética do RTQ-C (BRASIL, 2009c) nele, indicando um resultado positivo da etiquetagem em edifícios bioclimáticos.

\section{Princípios de bioclimatismo aplicados à arquitetura em clima tropical quente e úmido}

Segundo o Balanço Energético Nacional (BRASIL, 2006), edifícios públicos e comerciais representam cerca de $40 \%$ do consumo final de energia no país, sendo cerca da metade do valor consumido para prover conforto aos usuários dos edifícios.

A preocupação com a sustentabilidade do desenvolvimento das nações, dentro de um cenário de mudanças climáticas, provoca entre os arquitetos e urbanistas uma tendência de desenvolver suas tarefas usando todos os recursos e conhecimentos para reduzir impactos ambientais e maximizar o aproveitamento dos recursos naturais disponíveis.

Logo, a prática da arquitetura bioclimática representa grande trunfo nas ações que visam à melhoria do conforto térmico e lumínico nos ambientes construídos e a consequente diminuição do consumo de energia e do impacto ambiental.

Como uma das ferramentas para tal, tem-se a metodologia de análise de horas de desconforto (LAMBERTS; DUTRA; PEREIRA, 1997), que insere o arquivo de dados climáticos horários (temperatura e umidade do ar) do ano climático de uma cidade sobre a carta bioclimática de Givoni (1992), identificando as estratégias bioclimáticas para o projeto. No caso do Rio de Janeiro, cidade de clima quente e úmido e onde se localiza o Cresesb, como mostrado na Figura 1, a análise de horas de desconforto foi sistematizada na Tabela 1 e obteve-se que, em $20,8 \%$ das horas, o clima externo experimenta o estágio de conforto. Das demais horas, que totalizam $6.937,15 \%$ são desconfortáveis por frio (total de 1.314 horas), em sua maioria resolvidas com massa térmica para aquecimento, e 64,2\% são desconfortáveis pelo excesso de calor (total de 5.623 horas), sendo $61 \%$ solucionáveis com o incremento da ventilação 
natural. Apenas 3\% das horas anuais do Rio de Janeiro, segundo a análise bioclimática, realmente demandam o uso de ar-condicionado.

O diagrama indica ainda a elevada umidade relativa do Rio de Janeiro, que somada às altas temperaturas constituem grande fonte de desconforto. Nesse contexto, temos traçadas as principais estratégias para o conforto. Uma vez que $\mathrm{o}$ desconforto por frio assume segundo plano e visto que o desconforto pelo calor ocorre na maior parte do ano, as estratégias para o conforto se resumem a um projeto de arquitetura que vise ao aproveitamento eficiente da ventilação natural, incrementando as perdas por convecção e, logo, corrigindo as condições do excesso de umidade.

Segundo a NBR 15220-3 (ABNT, 2005), o terreno encontra-se na zona bioclimática 8 , ilustrada na Figura 2, devendo ter especial atenção para a ventilação como estratégia de condicionamento térmico passivo, reforçando as conclusões traçadas a partir do Diagrama de Givoni. As aberturas devem ser amplas e sombreadas, as paredes e coberturas devem ser leves e refletoras, o que avaliza e complementa a bibliografia citada.

Ao projetar uma edificação visando atender aos conceitos do bioclimatismo na arquitetura, observa-se a importância de definir estratégias bioclimáticas nos estágios iniciais do projeto. A Figura 3 a seguir representa, no eixo horizontal, as etapas sucessivas de desenvolvimento do projeto e, no eixo vertical, o grau de restritividade de aplicação das estratégias. À medida que as etapas de projeto vão sendo realizadas, reduz-se a liberdade de escolhas e de reelaboração, pois aumentam, inversamente, as restrições oriundas das interfaces com os demais projetos complementares. Por exemplo, a orientação da edificação deve ser planejada para receber o vento fresco dominante, associada à ventilação cruzada já no estudo preliminar, pois nas etapas subsequentes o projeto já se encontra estruturado, conforme ilustrado na Figura 3, a seguir.

A ventilação cruzada deve adequar-se às necessidades dos usuários, por meio da correta localização e dimensionamento das aberturas. Tais decisões devem ser complementadas pela escolha de esquadrias capazes de direcionar o fluxo de ar, seja por retirada de ar quente da camada mais alta do ambiente com direcionamento de fluxo para o usuário ou somente visando à ventilação higiênica. O uso de elementos direcionadores do fluxo do ar para o interior da edificação pode ser uma opção, quando o vento dominante e as aberturas possuem direções distintas. Ambientes fluidos permitem que a brisa percorra o maior número de espaços da edificação. Existe ainda o efeito chaminé, capaz de fazer a retirada de ar quente e, consequentemente, de forçar a entrada de ar frio, muito utilizado em situações em que não há disponibilidade de vento.

Elementos externos à edificação como pergolados, brises, varandas e marquises garantem o sombreamento e a diminuição da incidência de radiação solar direta, permitindo somente a entrada de luz natural. O tratamento do entorno do edifício também pode favorecer a diminuição da temperatura do ar que entra nos ambientes, utilizando-se, por exemplo, árvores, arbustos e forrações.

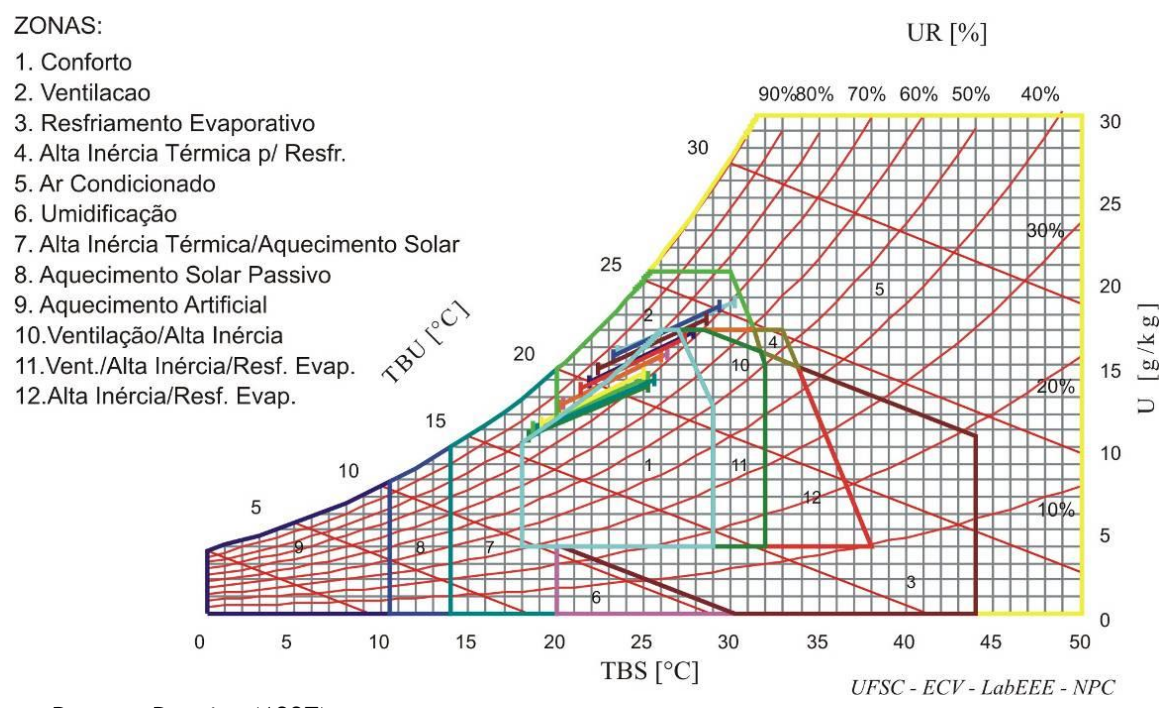

Fonte: Lamberts, Dutra e Pereira (1997).

Figura 1 - Diagrama bioclimático para a cidade do Rio de Janeiro, com dados de normais climatológicas 


\begin{tabular}{|c|c|c|c|}
\hline & Zona & $\%$ horas & Total \% horas \\
\hline Conforto & & & 20,8 \\
\hline \multirow{4}{*}{$\begin{array}{l}\text { Desconforto } \\
\text { por calor }\end{array}$} & Ventilação & 61 & \multirow{4}{*}{64,2} \\
\hline & Massa térmica para resfriamento & 0,1 & \\
\hline & Resfriamento evaporativo & 0,1 & \\
\hline & Ar condicionado & 3 & \\
\hline \multirow{2}{*}{$\begin{array}{l}\text { Desconforto } \\
\text { por frio }\end{array}$} & Massa térmica para aquecimento & 14,8 & \multirow{2}{*}{15} \\
\hline & Aquecimento solar passivo & 0,2 & \\
\hline
\end{tabular}

Fonte: Mello (2006 apud LAMBERTS; DUTRA; PEREIRA, 1997).

Tabela 1 - Horas de conforto e desconforto para o Rio de Janeiro

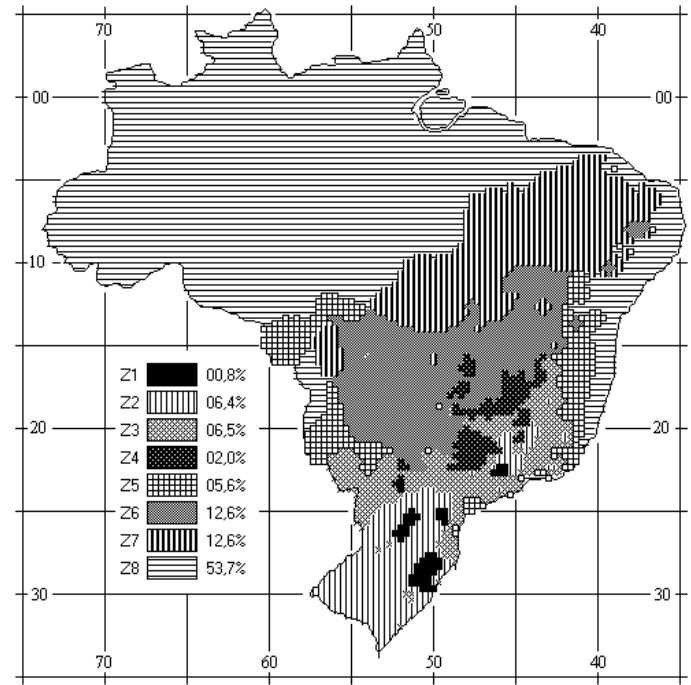

Fonte: NBR 15220-3 (ABNT, 2005).

Figura 2 - Zoneamento bioclimático brasileiro

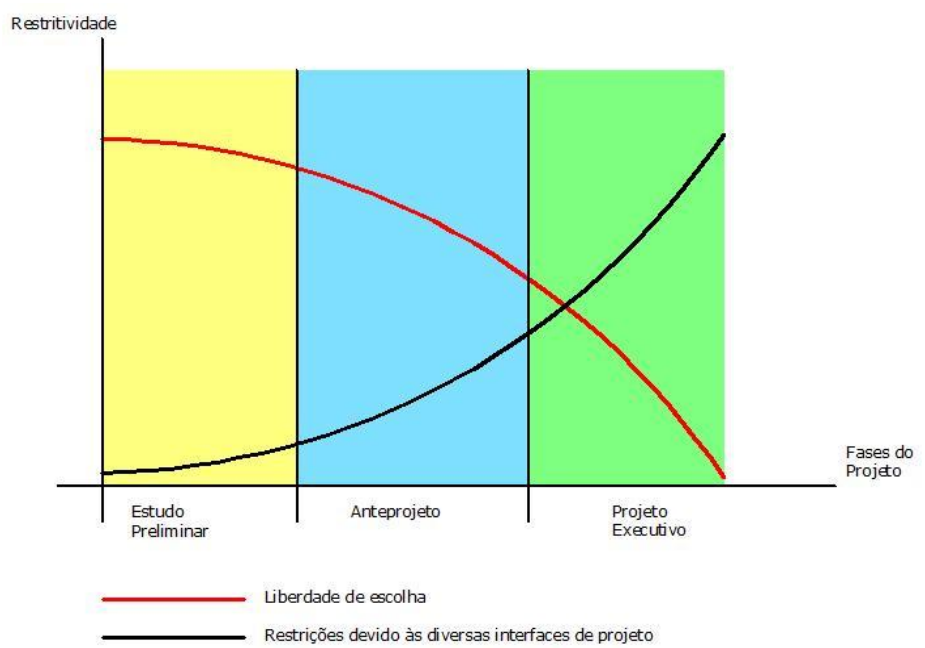

Fonte: Adaptado de Barroso-Krause (2005).

Figura 3 - Ilustração representativa da liberdade $x$ restrições de escolha durante as fases de projeto 


\section{Descrição do prédio com aplicação dos princípios de bioclimatismo}

\section{Localização}

O terreno do Centro de Informações do Cresesb localiza-se na cidade do Rio de Janeiro, na Ilha do Fundão, Cidade Universitária, Brasil, Latitude: $22^{\circ}$ 51' S, Longitude: 43 14' O, nas margens da Baía de Guanabara, conforme mostram as Figuras 4 e 5, a seguir.

\section{Partido arquitetônico}

Conforme citado anteriormente, a concepção de uma edificação que tire partido do meio em que se insere tem início na escolha de sua implantação no terreno, privilegiando a orientação desejada e articulando os espaços internos de maneira que recebam a insolação e a iluminação adequadas.

O terreno abriga outros edifícios do Cepel, e o Centro será construído nos fundos da sede, próximo à Casa Solar Eficiente. O local escolhido para a implantação do conjunto preserva a vegetação existente, valorizando um frondoso ipêrosa, ao passo que o resguarda da sombra das demais edificações, importante para a captação e utilização da energia solar através de painéis fotovoltaicos.

O programa fornecido pelo Cresesb foi dividido em três partes funcionais, que caracterizam três blocos distintos, porém interligados: (a) recepção/hall, exposição, copa e sanitários;

(b) sala de aula/auditório; e

(c) escritórios, sala de estudos/biblioteca, depósito e sala de utilidades.

Cada parte representa um bloco distinto, todos articulados em torno de um jardim: uma área de estar provedora de conforto térmico e visual. Partindo do jardim em direção à Casa Solar estará o parque de exposições, que abrigará equipamentos de energia solar e eólica.

A Figura 6 mostra a planta baixa do projeto de arquitetura, e as Figuras 7 e 8, três perspectivas.

$\mathrm{O}$ acesso à edificação é feito pela recepção, que, junto com a sala de exposições, forma o bloco central. A partir deste o público tem acesso à sala de aula e à sala de estudos, assim como ao jardim externo, para o qual está voltada a copa. O acesso aos escritórios e depósitos é restrito aos funcionários.

Esse bloco central localiza-se longitudinalmente ao eixo norte-sul. As fachadas leste e oeste são cegas, enquanto a norte é composta de portas pivotantes opacas, que funcionam como brises soleils móveis. A fachada sul tem grande percentual de área de abertura, composta de esquadrias com vidro e aberturas para ventilação e para acesso externo ao jardim. Essa grande área de abertura transparente é protegida da radiação solar direta, incidente no mês de dezembro, pelo avanço do beiral da cobertura, complementado pelo sombreamento oferecido pela árvore (ipê-rosa) localizada na frente dessa fachada.

Fonte: Fundação CIDE.

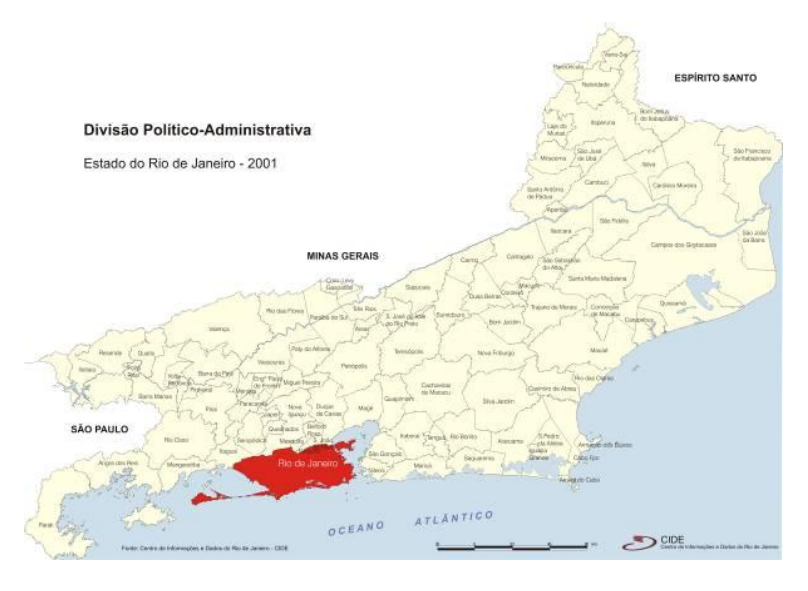

Figura 4 - Localização do município do Rio de Janeiro no estado do Rio de Janeiro 
Fonte: Instituto Pereira Passos.

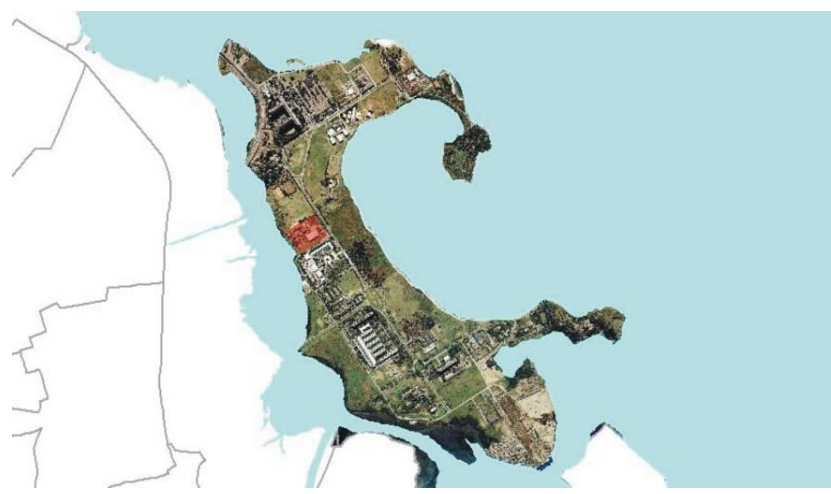

Figura 5 - Foto aérea da Cidade Universitária com marcação do terreno do projeto

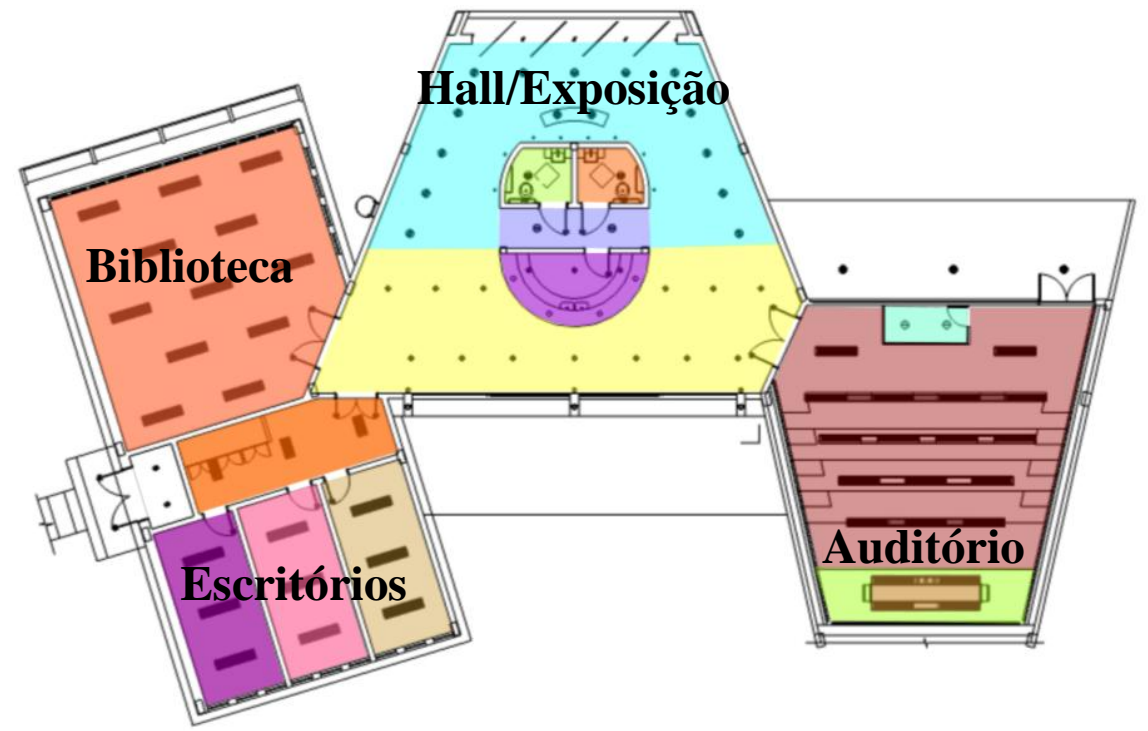

Figura 6 - Planta de arquitetura do Centro de Informações do Cresesb

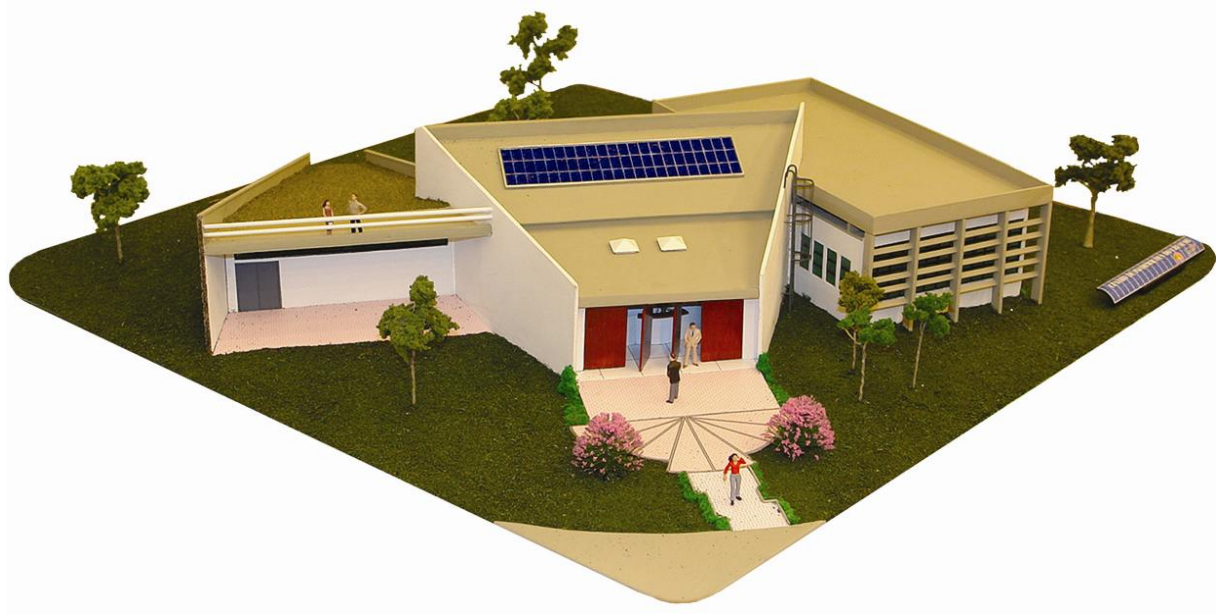

Figura 7 - Maquete do prédio vista a partir do norte 


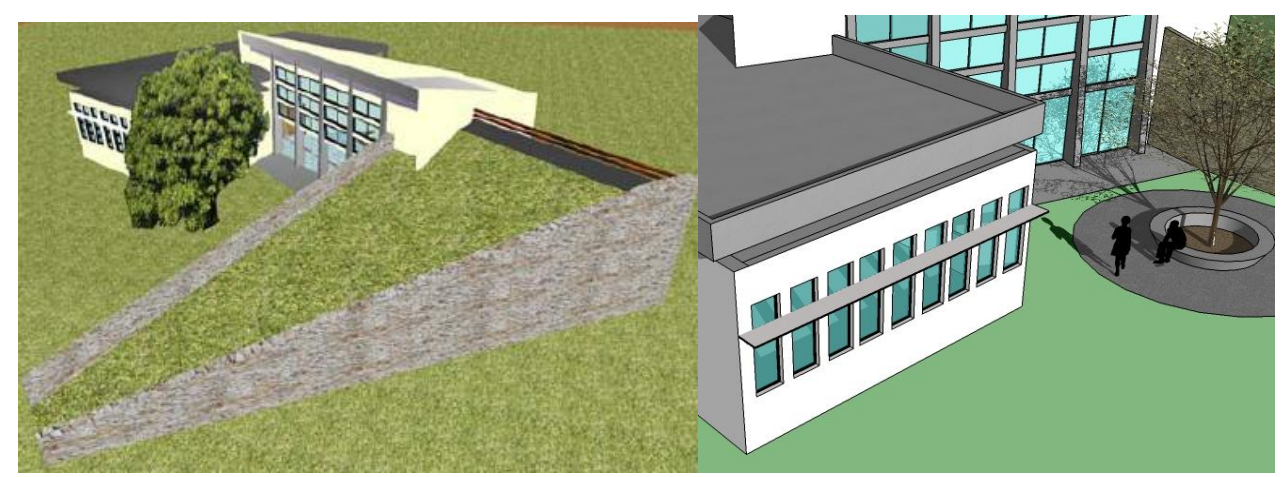

Figura 8 - Vista SE do prédio - Bloco Leste com cobertura naturada, Bloco Sul com fachada envidraçada e Bloco Oeste com prateleira de luz (detalhe à direita)

O segundo bloco abriga a sala de aula e foi projetado para ser isolado. Para isso, os fechamentos laterais foram feitos com paredes duplas com colchão de ar, enquanto a cobertura foi composta de uma laje de concreto com camada vegetal. Essa cobertura tem inclinação acentuada, que, conjugada com o nível semienterrado da sala de aula, resulta em um jardim suspenso que toca o chão, permitindo acesso ao público. A iluminação natural da sala é garantida pela esquadria em linha localizada na fachada norte, que contém também portas de acesso independentes e/ou escapes.

O terceiro bloco é compartilhado entre o público e os funcionários do Centro, cuja área de trabalho tem acesso restrito. Essa divisão é feita por um grande armário de depósito, que separa os escritórios da sala de estudos. Esta tem uma empena de caixilhos de concreto com vidro fixo orientada para nordeste e, por isso, foi protegida por uma colmeia de brises. A fachada noroeste, de grande extensão nesse bloco, tem parede de tijolo deitado e é externamente protegida por vegetação.

Os três blocos têm diferentes alturas e formas, que se unem em um interior único, centralizado pelo volume central que abriga a sala de exposições e o acesso ao conjunto. É a partir desse espaço que o público tem acesso ao Parque de Exposição; liga o Centro à Casa Solar existente.

Os espaços de uso frequente e permanente durante o dia - os escritórios - foram orientados na direção sudeste. Devido à planta alongada desses espaços, projetou-se uma prateleira de luz sobre as janelas para otimizar a distribuição uniforme da iluminação natural. A sala de exposição, cujas aberturas localizam-se na fachada sul, também recebe boa contribuição da luz natural sem ganho de carga térmica, pois a radiação solar não incide nela diretamente.

Como ponto de partida, o projeto ficou restrito a uma área de construção previamente estabelecida além de limites orçamentários para sua construção. Adotando critérios de bioarquitetura, o projeto apresenta linhas arquitetônicas diferenciadas, com soluções criativas para a integração do sistema fotovoltaico conectado à rede à edificação (BIPV Building Integrated Photovoltaics). Os painéis fotovoltaicos foram integrados à arquitetura em suas condições ótimas de funcionamento, quanto à orientação e à inclinação.

O período de ocupação do Centro de Informações do Cresesb é das 8 h00 às 17 h00, que é seu horário de funcionamento. Para calcular as horas de desconforto do período de ocupação da edificação utilizaram-se as temperaturas BIN anuais para o Rio de Janeiro (GOULART et al., 1998). Considerando o intervalos das $7 \mathrm{~h} 00$ às $12 \mathrm{~h} 00 \mathrm{e}$ das $13 \mathrm{~h} 00$ às $18 \mathrm{~h} 00$, teremos o total de 4.368 horas anuais, das quais $83,77 \%$ encontram-se dentro da zona de conforto estabelecida na NBR 15220-3 (ABNT, 2005). Das horas de desconforto, 1,72\% são por frio, e 14,51\% são por calor. Isso justifica a adoção de recursos bioclimáticos de projeto em prol da redução do ganho térmico da edificação.

As diretrizes gerais do projeto foram:

(a) aproveitamento passivo dos recursos naturais;

(b) racionalização no uso de energia;

(c) uso de fontes renováveis de energia, transformada na própria edificação;

(d) racionalização do uso da água;

(e) qualidade do ar e ambiente interior;

(f) conforto termoacústico;

(g) uso da luz natural;

(h) uso de tecnologias sustentáveis; e

(i) utilização de produtos com certificação ISO 14001 . 


\section{Recursos bioclimáticos e tecnologias eficientes e inovadoras}

Utilizaram-se no projeto diversas tecnologias construtivas, com o objetivo de tornar a edificação mais sustentável, seja do ponto de vista energético ou ambiental. Todas elas se relacionam e se complementam de uma forma holística. São elas:

(a) cobertura naturada;

(b) ventilação cruzada;

(c) laje e parede duplas, com colchão de ar;

(d) utilização das águas de chuva;

(e) uso racional de água potável com especificação de equipamentos eficientes;

(f) elementos de proteção solar;

(g) iluminação artificial eficiente e integrada à natural;

(h) fontes alternativas de energia - energia solar; e

(i) emprego de materiais e equipamentos que garantam conforto ambiental com eficiência energética: esquadrias, luminárias e arcondicionados.

\section{Cobertura naturada}

Sobre a sala de aula está previsto um jardim visitável instalado sobre uma laje de concreto com uma camada de drenagem que protege a impermeabilização. Os objetivos dessa cobertura são: reduzir o aporte de águas pluviais à rede de drenagem urbana, contribuindo para a redução de enchentes; aumentar a evapotranspiração nas áreas urbanas, contribuindo para a redução das ilhas de calor; diminuir o aporte de carga térmica no pavimento inferior; utilizar as águas das chuvas; e aumentar a vida útil da impermeabilização, já que funciona como excelente proteção mecânica.

O investimento excedente para tornar uma cobertura de laje de concreto simples em uma cobertura com naturação (vegetal) é relativamente pequeno.

O custo de realização de um jardim com drenagem própria sobre a laje existente foi orçado na época, pelo sistema EMOP, em R \$ 2.200,00. Adotando-se uma vida útil para tal sistema de 20 anos, com uma taxa de juros de $12 \%$ a.a., chega-se ao custo anualizado de $\mathrm{R} \$ 2$ 294,50. Por outro lado, o benefício anual atualizado é o próprio custo da redução de demanda e de consumo de energia elétrica para o mesmo ano, de $\mathrm{R} \$ 963,70$, considerando-se a redução de energia de $1,13 \mathrm{kWh}$ e de demanda de $2.180 \mathrm{~W}$, estimativas realizadas por Silva Filho (2007), através de simulações usando o VisualDOE e TRY do Rio de Janeiro e demais dados apresentados em sua tese; e, ainda, as respectivas tarifas de $108,00 \mathrm{R} \$ / \mathrm{MWh}$ e de 442,00 R\$/kW.

Para o cálculo dos custos anualizados utilizou-se a Fórmula 1, abaixo, da matemática financeira, que transforma um valor inicial em uma série de $n$ pagamentos a uma taxa $\mathrm{j}$, conforme a metodologia do Prêmio Procel (LOMARDO et al., 2007b). O custo anualizado é calculado considerando-se a vida útil dos equipamentos ( $\mathrm{n}$ anos). Sempre que a relação custo-benefício for menor que a unidade, ou seja, o benefício anual for superior ao custo anualizado, o investimento será vantajoso.

Assim: $\mathrm{Ca}=\mathrm{C}_{0} \times \frac{\mathrm{j} \times(\mathrm{j}+1)^{\mathrm{n}}}{(1+\mathrm{j})^{\mathrm{n}}-1}$

Eq. 1

Onde:

Ca: custo anualizado;

$\mathrm{C}_{0}$ : custo na data zero;

$\mathrm{J}$ : taxa de juros; e

$\mathrm{N}$ : vida útil.

Fazendo então:

$$
\begin{aligned}
& \mathrm{C}_{\mathrm{a}}=2200,00 \times 0,12 \times(0,12+1)^{20}=\mathrm{R} \$ 294,50 \\
& (1+0,12)^{20}-1
\end{aligned}
$$

A estimativa da demanda média mensal de energia elétrica foi extraída de pesquisa realizada por Silva Filho (2007), que simulou o comportamento do edifício para diversas opções de cobertura usando o software VisualDOE, e está apresentada na Figura 9. O resultado obtido comprova que a proposta de uso da cobertura naturada no projeto permitirá um menor consumo de energia ao longo do ano e identifica cobertura de telha cerâmica como a proposta de maior consumo de energia. 
DEMANDA MENSAL DE E.E.

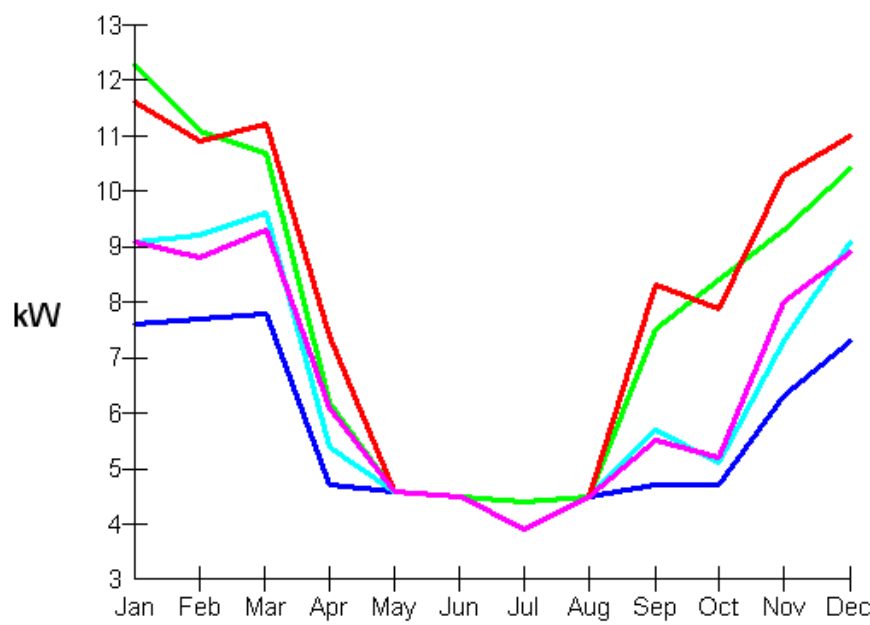

COMPARAÇÃO - TODAS AS ALTERNATIVAS

\section{ALTERNATIVAS}

- Cobertura naturada

- Laje de concreto

impermeabilizado

- Telha metálica sanduíche

- Telha cerâmica

- Laje de concreto com

material isolante

Fonte: Silva Filho (2007).

Figura 9 - Gráfico comparativo entre as alternativas de cobertura

\section{Ventilação cruzada}

De acordo com a Carta Bioclimática para o Rio de Janeiro, a ventilação é uma estratégia bioclimática indicada para $61 \%$ das horas (LAMBERTS; DUTRA; PEREIRA, 1997). Sendo assim, o projeto utilizou como principal estratégia de ventilação a natural cruzada, que irá viabilizar o conforto térmico na maior parte das horas de desconforto por calor do ano $(64,4 \%)$ e, consequentemente, redução do consumo de energia elétrica pelo não uso de ventiladores e outros equipamentos.

A ventilação cruzada permite a circulação do ar dentro do ambiente da sala de exposição e recepção, renovando o ar e melhorando a sensação térmica no interior da edificação. Os vãos projetados promovem correntes de circulação de ar na altura do usuário, o que proporciona a sensação de frescor pela convecção do ar e evaporação do suor da pele.

A área de ventilação definida respeitou a recomendação de $40 \%$ da área do piso constante na NBR 15220-3: Desempenho Térmico de Edificações, Parte 3: Zoneamento bioclimático brasileiro e diretrizes construtivas para edificações unifamiliares de interesse social (ABNT, 2005). Cabe ressaltar que as recomendações da norma não devem ser generalizadas para todas as tipologias arquitetônicas, visto que foram elaboradas para determinado tipo de edificação. No caso do Centro, buscou-se empregá-las devido à premissa de projeto que valorizou o condicionamento passivo para a garantia das condições de conforto do usuário - premissa também comum às edificações unifamiliares de interesse social. Os sistemas ativos de manutenção do conforto - ar condicionado e iluminação artificial - foram projetados para ser usados em situações climáticas extremas ou específicas.

\section{Laje e parede duplas, com colchão de ar}

Sobre o bloco dos escritórios e sala de estudos projetou-se uma laje dupla com colchão de ar ventilado, diminuindo o ganho térmico e também possibilitando testar essa tecnologia construtiva. Já no bloco da sala de aula, fez-se uma parede dupla também com colchão de ar, que, além da redução de ganho térmico, permite a facilitação da instalação e a manutenção dos equipamentos de áudio, vídeo e iluminação desse ambiente.

\section{Utilização das águas de chuva}

O projeto do Centro de Informações do Cresesb incluiu em seus recursos bioclimáticos a captação e o uso da água da chuva para a rega da cobertura naturada, diminuindo o custo de manutenção extra decorrente da adoção dessa solução construtiva. Assim, foi projetada uma cisterna especial ligada a um filtro de água que descarta a primeira chuva. Desta há uma ligação de água diretamente com os pontos de rega.

De acordo com o Manual de Conservação e Reúso de Água em Edificações, produzido pela Agência Nacional de Águas e pela Federação das Indústrias do Estado de São Paulo (ANA; FIESP, 2005), a utilização de água da chuva para bacias sanitárias, limpeza de pisos e rega de jardim deve atender aos padrões de água de reúso das classes 1 e 3, a fim de garantir a saúde do usuário, a vida útil dos sistemas envolvidos e a integridade das plantas. 
Quanto à viabilidade climática para a adoção dessa tecnologia, basta observar o gráfico climatológico de médias mensais de precipitação para o Rio de Janeiro fornecido pelo Instituto Nacional de Meteorologia, mostrado na Figura 10. Mesmo nos meses com menor precipitação (até $40 \mathrm{~mm}$ ) ainda existe a possibilidade de se manter o reservatório de água da chuva abastecido.

O cálculo da viabilidade financeira do uso água de chuva considerou volume da cisterna para irrigação de $25 \mathrm{~m}^{3}$. Esta foi previamente calculada para otimizar o aproveitamento dos $402 \mathrm{~m}^{2} \mathrm{de}$ cobertura do edifício para as pluviosidades mensais do Rio de Janeiro. No período de verão, o volume de água captado poderá exceder a capacidade de armazenagem da cisterna, e o excesso será descartado na rede de águas pluviais, mas com isso o reservatório não ficará extremamente ocioso nos meses de estiagem.

A tarifa da água fornecida pela Cedae, na época, era de R\$ 2,58/1.000 L. Uma vez que a área da cobertura é de $402,00 \mathrm{~m}^{2}$, um reservatório de 25 $\mathrm{m}^{3}$ foi estimado, considerando-se a pluviosidade média para o Rio de Janeiro. Os custos englobaram uma cisterna extra ( $\mathrm{R} \$ 3.000,00)$, um prolongamento $(\mathrm{R} \$ 100,00)$ às tubulações pluviais - que existiriam, de qualquer forma, mesmo sem a instalação do sistema de captação da água pluvial e um filtro ( $\mathrm{R} \$ 800,00)$. Foram consideradas as respectivas vidas úteis para esses equipamentos: 50 anos, 50 anos e 20 anos.

Aplicando-se a Fórmula 1, anteriormente apresentada, para obter-se o valor anualizado da cisterna, cuja vida útil é de 50 anos, com taxa de juros anual, faz-se:

$$
\mathrm{C}_{\mathrm{a}}=\frac{3000 \times 0,12 \times(0,12+1)^{50}}{(1+0,12)^{50}-1}=\mathrm{R} \$ 361,25
$$

O mesmo raciocínio se fez para o filtro, cuja vida útil é menor, e para a adaptação da tubulação de águas pluviais, chegando ao total anualizado dos componentes de $\mathrm{R} \$ 480,40$.

Já para o cálculo dos benefícios, estes se referem à não utilização da água potável fornecida pela concessionária (Cedae), habitualmente usada para irrigar um grande jardim existente na cobertura e na área adjacente. $\mathrm{O}$ benefício atualizado é então o volume economizado em um ano $\left(300 \mathrm{~m}^{3}\right)$, multiplicado pela tarifa da água $\left(\mathrm{R} \$ 2,58 / \mathrm{m}^{3}\right)$, o que totaliza $\mathrm{R} \$ 774,00$, superior ao custo anualizado, que é R\$361,25. Porém, convém lembrar que os custos da água tendem a ser crescentes, na medida em que é esperado que aumente o estresse hídrico local.

\section{Uso racional da água potável com especificação de equipamentos eficientes}

O sistema de abastecimento de água convencional do projeto adotou medidas de conservação de água através de aparelhos eficientes como bacia de caixa acoplada de baixo consumo (6 litros por descarga) e arejadores para torneiras que mantêm a vazão constante de 6 litros por minuto. Essa escolha acarreta grande economia de água mensal (vide Tabela 2), quando comparada ao emprego de aparelhos convencionais, com estimativa de retorno de investimento em cerca de 84 dias.

\section{Elementos de proteção solar}

Os brises são reconhecidos por seus benefícios em relação à redução do ganho térmico nas edificações. Neste projeto, eles foram utilizados na fachada nordeste, onde a radiação solar incide diretamente durante a maior parte do ano. Uma malha de brises soleils verticais e horizontais foi disposta à frente da empena construída com caixilharia de concreto e vidro, que delimita a sala de estudo, garantindo conforto térmico desse espaço, com pouca redução de luminosidade natural. Também as portas pivotantes da entrada principal, voltadas para norte, funcionam como brises verticais móveis, controlando facilmente a incidência solar sobre o interior da recepção.

Ainda visando à otimização do uso da luz natural, foram instaladas prateleiras de luz nas janelas dos escritórios, cuja volumetria alongada dificultaria a distribuição homogênea da luz proveniente das aberturas.

Outra medida adotada no projeto foi o emprego de grandes aberturas na fachada sul, devidamente protegidas da radiação solar direta no verão, tanto pela presença de vegetação no exterior - um frondoso ipê-rosa - quanto pelo grande beiral da cobertura. 


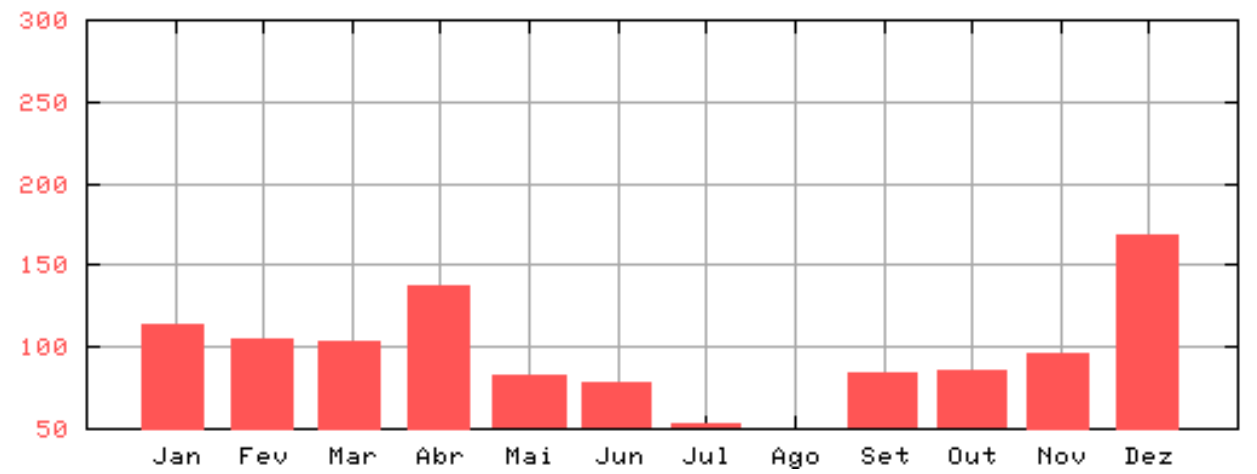

Fonte: Brasil (2010).

Figura 10 - Normais da precipitação para a Estação Santos Dumont no período 1961-1990

\begin{tabular}{l|l|l}
\hline Aparelho convencional & \multicolumn{1}{|c}{ Aparelho eficiente } & Economia (\%) \\
\hline Bacia sanitária de caixa acoplada: & Bacia sanitária de caixa acoplada com dois fluxos: & \\
160 usuários & 160 usuários & \\
6 litros de água por descarga & 6 litros de água por descarga (30\% dos casos) & \\
Total: 960 litros & 3 litros de água por descarga (70\% dos casos) & \multirow{3}{*}{ T36 litros (35\%) } \\
\hline Torneira sem arejador & Total: $\mathbf{6 2 4}$ litros & \\
200 usuários & 200 usuários & \\
10 litros por minuto & 6 litros por minuto & $\mathbf{8 0 0}$ litros (40\%) \\
Total: $\mathbf{2 . 0 0 0}$ litros & Total: $\mathbf{1 . 2 0 0}$ litros & $\mathbf{1 . 1 3 6}$ litros (38\%) \\
\hline
\end{tabular}

Tabela 2 - Consumo de água em aparelhos convencionais e eficientes

\section{Iluminação artificial eficiente e integrada à natural}

O partido adotado para a iluminação prevê a complementação da luz natural com a luz artificial obtida com conjuntos de iluminação constituídos de luminárias refletivas, lâmpadas de alta eficiência luminosa $(28 \mathrm{~W})$ e reatores eletrônicos, todos atendendo à especificação de $70 \%$ de rendimento, seguindo recomendações do Cepel.

A relação custo-benefício para uma situação de substituição do sistema de iluminação convencional - luminárias simples e lâmpadas de 40 W - por sistema mais eficiente - luminárias reflexivas e lâmpadas de $28 \mathrm{~W}$ - considera o tempo de uso diário para dias úteis de $12 \mathrm{~h} /$ dia em 312 dias por ano. O custo anualizado ( $\mathrm{R} \$ 288,80)$ será inferior ao benefício anual $(\mathrm{R} \$ 432,60)$ em cerca de $\mathrm{R} \$$ 143,80 ao ano. Apresentamos na Tabela 3, abaixo, os dados para os cálculos da anualização dos custos dos equipamentos, que foram calculados usando-se a Fórmula 1, anteriormente apresentada, e a taxa de juros igual a $12 \%$ a.a.

\section{Fontes alternativas de energia - energia solar}

A energia solar será convertida em energia elétrica por coletores fotovoltaicos que ocupam uma área de $40 \mathrm{~m} 2$. A energia necessária para o prédio será gerada por células fotovoltaicas, instaladas na cobertura. Previu-se um sistema sincronizado com a rede elétrica local para o atendimento dos períodos em que a radiação solar for insuficiente.

Os sistemas fotovoltaicos conectados à rede geralmente são associados a uma edificação e realizam a injeção direta de toda a energia excedente na rede elétrica, sem qualquer armazenamento em baterias.

O consumo máximo diário de energia elétrica estimado para o Centro é da ordem de 95,3 $\mathrm{kWh} /$ dia. O consumo anual estimado é de cerca de $22.850 \mathrm{kWh}$. Para uma previsão mais detalhada do consumo de energia elétrica para iluminação e ar condicionado, preparou-se uma simulação com a utilização do programa VisualDOE. Os resultados obtidos são mostrados na Figura 11. 


\begin{tabular}{l|c|c|c|c|c|c|c}
\hline Equipamentos & Quant. & $\begin{array}{c}\text { Vida } \\
\text { útil } \\
\text { (anos) }\end{array}$ & $\begin{array}{c}\text { Custo } \\
\text { inicial }\end{array}$ & $\begin{array}{c}\text { Custo } \\
\text { anualizado }\end{array}$ & $\begin{array}{c}\text { Energia } \\
\text { economizada } \\
\text { (MWh/ano) }\end{array}$ & $\begin{array}{c}\text { Redução } \\
\text { da } \\
\text { demanda } \\
\text { em kW }\end{array}$ & Benefício \\
\hline Luminária & 21 & 10 & 2.520 & 446 & 0,00 & 0,00 & 0,00 \\
\hline Lâmpada 40 W & 42 & 2 & 179 & 108 & 0,00 & 0,00 & 0,00 \\
\hline Reator convencional & 21 & 4 & 420 & 138 & 0,00 & 0,00 & 0,00 \\
\hline Total (R\$) & & & $3.118,5$ & 692,2 & & & 0,00 \\
\hline Luminária & 21 & 10 & 4.620 & 817,7 & & & 0,0 \\
\hline Lâmpada 28 W -16.000 h & 42 & 4 & 344 & 113,1 & 1,58 & 0,50 & 393,2 \\
\hline Reator eletrônico & 21 & 20 & 374 & 50,1 & 0,16 & 0,05 & 39,3 \\
\hline Total (R\$) & & & 5.338 & 980,8 & & & 432,6 \\
\hline Diferença dos Casos 1 e 2 (R\$) & & & & 288,8 & & & 432,6 \\
\hline
\end{tabular}

Fonte: Lomardo et al. (2007a).

Tabela 3 - Dados para o cálculo da relação custo-benefício (RCB) com uso de equipamentos mais eficientes: tempo de retorno e economia de energia no Cresesb

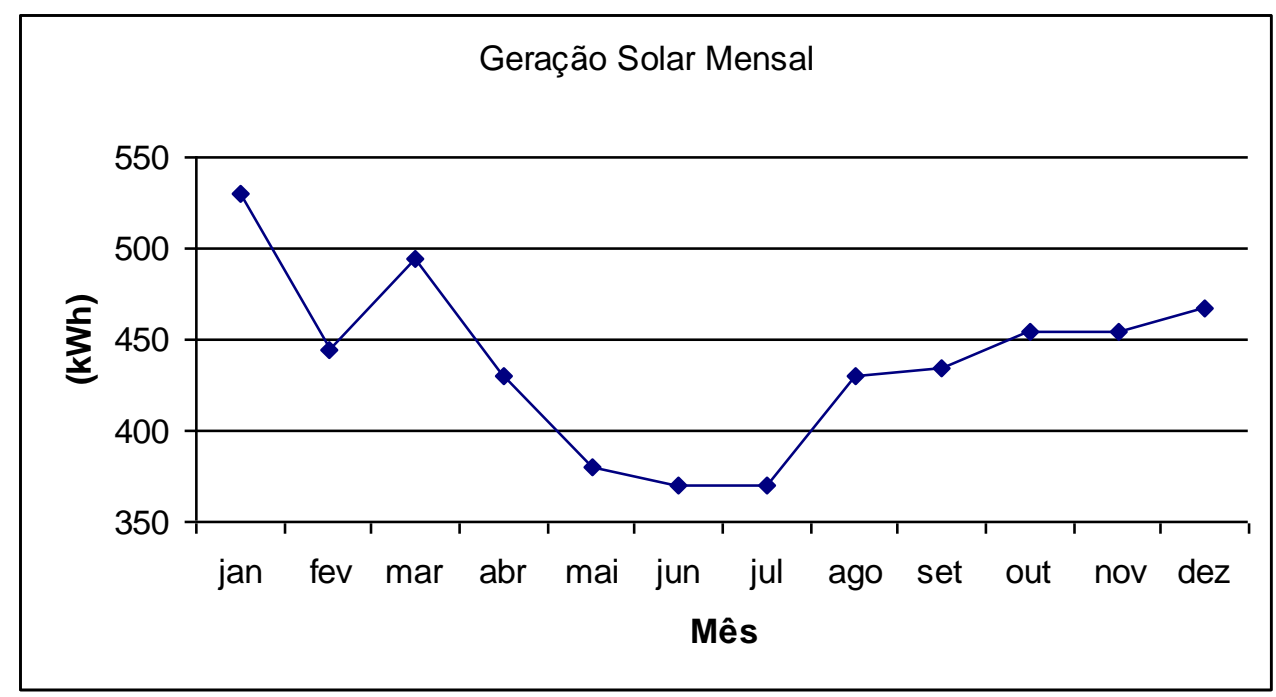

Fonte: Galdino et al. (2007).

Figura 11 - Previsão do total de energia gerada (kWh) a cada mês

O Centro de Informações do Cresesb possuirá um sistema fotovoltaico conectado à rede elétrica com potência instalada de $4 \mathrm{kWp}$. Essa tecnologia, embora ainda considerada distante da realidade brasileira, deverá ter uma importância mundial crescente num futuro próximo. O prédio será totalmente monitorado por meio de um sistema de aquisição de dados, que aferirá parâmetros ambientais e de consumo/geração de energia.

A tecnologia empregada no novo sistema se baseia em painel fotovoltaico de c-Si (silício cristalino) e inversores para conexão à rede do tipo SunnyBoy, incluindo uma otimização no dimensionamento do painel fotovoltaico.

Isso indica que a geração de energia total anual será de $5.262 \mathrm{kWh}$ e que a média diária anual de geração de energia será de 14,4 kWh. A fração solar dessa geração corresponde a aproximadamente $23 \%$ do consumo anual previsto para a edificação.

Faltam dados a respeito dos benefícios ambientais e sociais - emissões evitadas, áreas não alagadas, etc. - , que também deveriam ser considerados na avaliação do custo-benefício dessa proposta.

\section{Materiais e equipamentos utilizados: esquadrias, luminárias e ar-condicionados}

As alvenarias projetadas são de blocos de concreto para vedação, cujo colchão de ar garante pouco ganho térmico para as edificações no Rio de Janeiro (MELLO, 2006). Os vidros especificados para as janelas são verdes, também mais indicados para o clima local quanto à redução do ganho térmico.

Todas as luminárias especificadas apresentam refletância mínima de $70 \%$, seguindo as 
recomendações do Cepel/Eletrobras, e todos os aparelhos de ar condicionado especificados são do tipo split e classificados, na época do projeto, na categoria A, logo com o selo Procel. As unidades condensadoras foram sombreadas para criar um ambiente que otimize seu funcionamento e seu consumo energético.

\section{Avaliação da eficiência energética do edifício mediante a aplicação do RTQ-C}

Com o objetivo de verificar a eficiência energética do edifício projetado, a equipe do Laboratório de Conservação de Energia e Conforto Ambiental da Universidade Federal Fluminense (LabCECA/UFF) aplicou o RTQ-C (BRASIL, 2009c) pelo método prescritivo. Para a obtenção da etiqueta global, foram avaliados os três quesitos isoladamente: a envoltória e seus pré-requisitos específicos; o sistema de iluminação artificial e seus prérequisitos específicos; e, por fim, o sistema de condicionamento de ar com seus pré-requisitos específicos. Então, verificou-se a possibilidade da pontuação de bonificação.
O sistema de iluminação artificial atingiu o nível $\mathrm{C}$, com equivalente numérico igual a 2,75. A iluminância e a densidade de potência por ambiente também são apresentadas na Tabela 4 , abaixo. A densidade de potência média para toda a edificação é de 13,29 W/m2.

Todos os ambientes de permanência prolongada são opcionalmente condicionados de modo artificial (sistema híbrido), e o sistema alcançou o nível A, com EqNnumCA igual a 5, conforme a Tabela 5, abaixo. O auditório é o único ambiente em que o condicionamento artificial é obrigatório.

A envoltória atingiu nível A de eficiência, com correspondente equivalente numérico igual a 5 . Este artigo dá destaque à avaliação desse quesito, uma vez que ele está diretamente ligado às decisões de arquitetura do edifício, assim como ênfase é dada ao quesito de bonificação relacionado às soluções de projeto arquitetônico.

Cumpridos todos os pré-requisitos, foi possível manter esse nível A. Por fim, com a aplicação da equação geral, concluiu-se que o edifício atingiu nível global A de eficiência energética, o que lhe qualifica para receber o selo Procel.

\begin{tabular}{|c|c|c|c|c|c|c|c|}
\hline Ambiente & $\begin{array}{l}\text { Iluminância } \\
\qquad(\mathbf{l u x})\end{array}$ & Área $\left(m^{2}\right)$ & $\begin{array}{c}\text { Coef. de } \\
\text { ponde- } \\
\text { ração } \\
\end{array}$ & $\begin{array}{c}\mathbf{D P I}_{\mathbf{A}} \\
\left(\mathbf{W} / \mathbf{m}^{2}\right)\end{array}$ & EqNumDPI & Nível & $\begin{array}{c}\text { Resultado } \\
\text { ponderado }\end{array}$ \\
\hline Sala de estudos & 300 & 58,34 & 0,19 & 13,58 & 1 & $\mathrm{E}$ & 0,19 \\
\hline Utilidades & 200 & 3,07 & 0,01 & 10,42 & 3 & $\mathrm{C}$ & 0,03 \\
\hline Circulação & 100 & 13,95 & 0,04 & 7,31 & 1 & $\mathrm{E}$ & 0,04 \\
\hline Escritório A & 1000 & 13,48 & 0,04 & 14,69 & 5 & $\mathrm{~A}$ & 0,20 \\
\hline Escritório B & 1000 & 13,48 & 0,04 & 14,69 & 5 & $\mathrm{~A}$ & 0,20 \\
\hline Escritório C & 1000 & 13,48 & 0,04 & 14,69 & 5 & A & 0,20 \\
\hline $\begin{array}{l}\text { Cabine de } \\
\text { controle }\end{array}$ & 300 & 3,37 & 0,01 & 14,24 & 3 & $\mathrm{C}$ & 0,03 \\
\hline Tablado & 500 & 10,81 & 0,03 & 22,57 & 5 & A & 0,15 \\
\hline Sala de aula & 300 & 59,17 & 0,19 & 16,49 & 1 & $\mathrm{E}$ & 0,19 \\
\hline WC feminino & 150 & 3,07 & 0,01 & 12,70 & 1 & $\mathrm{E}$ & 0,01 \\
\hline WC masculino & 150 & 3,07 & 0,01 & 12,70 & 1 & $\mathrm{E}$ & 0,01 \\
\hline Copa & 300 & 7,85 & 0,02 & 13,38 & 4 & $\mathrm{~B}$ & 0,08 \\
\hline $\begin{array}{l}\text { Área de } \\
\text { exposições }\end{array}$ & 500 & 50,57 & 0,16 & 9,00 & 5 & A & 0,80 \\
\hline Circ. WCs & 100 & 5,02 & 0,02 & 13,15 & 1 & $\mathrm{E}$ & 0,02 \\
\hline Recepção & 500 & 52,52 & 0,17 & 12,28 & 4 & $\mathrm{~B}$ & 0,68 \\
\hline Total & & 311,25 & & & & C & 2,75 \\
\hline
\end{tabular}

Tabela 4 - Determinação do EqNumDPI do sistema de iluminação dos ambientes 


\begin{tabular}{l|c|c|c|c|c}
\hline Ambiente & Área $\left(\mathbf{m}^{\mathbf{2}}\right)$ & $\begin{array}{c}\text { Coef. de } \\
\text { ponderação }\end{array}$ & $\begin{array}{c}\text { EqNum } \\
\text { CA }\end{array}$ & Nível & $\begin{array}{c}\text { Resultado } \\
\text { ponderado }\end{array}$ \\
\hline Recepção, área de exposições e copa & 111,98 & 0,37 & 5 & $\mathrm{~A}$ & 1,85 \\
\hline Sala de estudos & 58,34 & 0,19 & 5 & $\mathrm{~A}$ & 0,95 \\
\hline Circulação & 13,95 & 0,05 & 5 & $\mathrm{~A}$ & 0,25 \\
\hline Escritório A & 13,48 & 0,05 & 5 & $\mathrm{~A}$ & 0,25 \\
\hline Escritório B & 13,48 & 0,05 & 5 & $\mathrm{~A}$ & 0,25 \\
\hline Escritório C & 13,48 & 0,05 & 5 & $\mathrm{~A}$ & 0,25 \\
\hline Sala de aula e cabine de controle & 76,47 & 0,25 & 5 & $\mathrm{~A}$ & 1,25 \\
\hline Total & $\mathbf{3 0 1 , 1 8}$ & & & $\mathrm{A}$ & $\mathbf{5}$ \\
\hline
\end{tabular}

Tabela 5 - Determinação do EqNumCA do sistema de condicionamento de ar dos ambientes

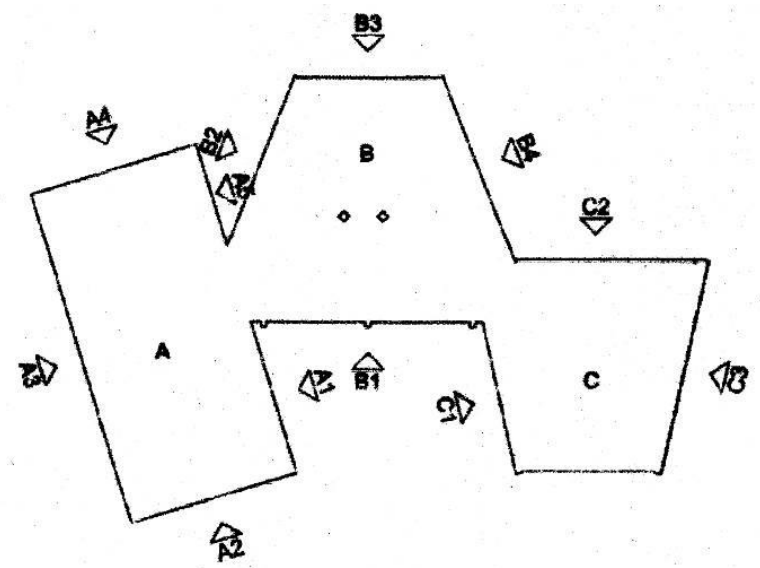

Figura 12 - Delimitação do perímetro do prédio considerado para os cálculos de áreas

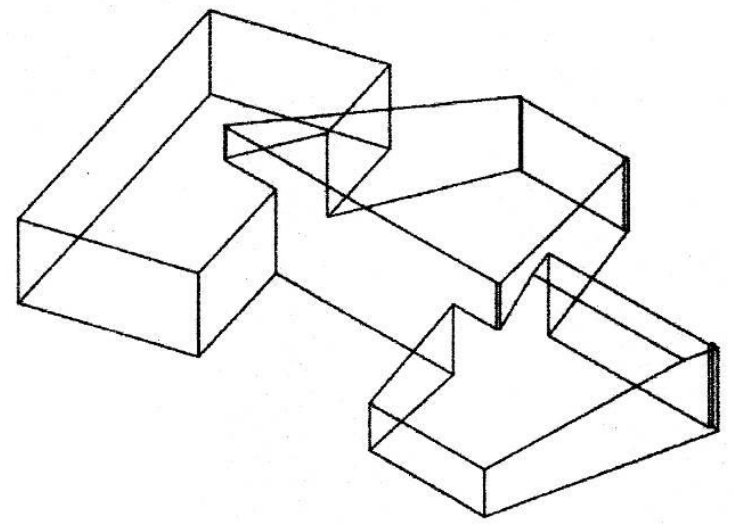

Figura 13 - Indicação do volume do prédio calculado

\section{Determinação do nível de eficiência energética da envoltória}

Com base nos desenhos de arquitetura já mostrados anteriormente, foram calculadas as áreas necessárias para a avaliação da eficiência da envoltória, conforme a Figura 12, que são: área de projeção do edifício; área total de piso; e área de projeção da cobertura, todas com o mesmo valor, uma vez que o edifício possui apenas um pavimento com cobertura, que abrange toda a área ocupada. Com isso, definiu-se o fator de altura, com valor igual à unidade.
Em seguida, foi calculada a área da envoltória como o somatório das áreas de fechamento opaco, envidraçados e cobertura. Para a obtenção do fator de forma, calculou-se o volume total do edifício, conforme ilustra a Figura 13, valor este adotado no cálculo do índice de consumo da envoltória ( $\left.\mathrm{IC}_{\mathrm{env}}\right)$.

Para o cálculo do percentual de aberturas nas fachadas, calculou-se, inicialmente, a área total de fachada, que inclui a área de fechamento opaco somada à área de envidraçado. Esse valor é adotado no cálculo do índice de consumo da envoltória $\left(\mathrm{IC}_{\mathrm{env}}\right)$, já que o edifício não possui 
aberturas na fachada oeste, o que minimiza o ganho térmico pelos envidraçados.

Para a determinação do potencial de sombreamento do edifício, foram calculados os ângulos de sombreamento vertical e horizontal. A preocupação com o sombreamento proporcionado pelos brises da fachada noroeste, pela cobertura em balanço, pela prateleira de luz na fachada sudeste e pelo próprio prédio (autossombreamento) auxiliou na redução dos ganhos de calor no interior e é uma vantagem contabilizada nesse quesito.

Uma vez que o edifício possui diversos tipos de vidro - incolor de $4 \mathrm{~mm}$, que permite maior ganho térmico, verde de $4 \mathrm{~mm}$ e temperado verde de 6 $\mathrm{mm}$, que permitem menores ganhos -, os valores de fator solar foram ponderados pelas áreas, e o resultado foi usado na fórmula para calcular o índice de consumo da envoltória ( $\left.\mathrm{IC}_{\mathrm{env}}\right)$ :

$\mathrm{IC}_{\text {env }}=454,47 . \mathrm{FA}-1641,37 . \mathrm{FF}+33,47 . \mathrm{PAF}_{\mathrm{T}}+$ 7,06. FS + 0,31. AVS - 0,29. AHS - 1,27. $\mathrm{PAF}_{\mathrm{T}}$. AVS $+0,33 . \mathrm{PAF}_{\mathrm{T}}$. AHS $+718=454,11$

Onde:

$\mathrm{FA}=1$;

$\mathrm{FF}=0,44$

$\mathrm{PAF}_{\mathrm{T}}=0,18$;

Fsponderado $=0,64$;

AVSponderado $=24,16$; e

AHSponderado $=37,59$.

Em seguida, os limites máximo e mínimo dos indicadores de consumo foram obtidos alterandose os parâmetros de percentual de abertura nas fachadas total, fator solar e ângulos de sombreamento vertical e horizontal. Seus valores estão apresentados na Tabela 6, a seguir.

O $\mathrm{IC}_{\text {env }}$ obtido determinou a classificação A para a envoltória do edifício, lhe garantindo o equivalente numérico (EqNumEnv) igual a 5, ilustrado na Figura 14, a seguir.

\section{Verificação do atendimento aos pré- requisitos específicos da envoltória}

Após esse cálculo, verificou-se o cumprimento aos pré-requisitos específicos: transmitância da cobertura, transmitância das paredes, absortância das paredes e cobertura e percentual de aberturas zenitais.

O projeto de arquitetura prevê a construção de diversos tipos de cobertura. Aquela sobre os escritórios é composta de materiais isolantes térmicos sobre a laje de concreto, combinadas à câmara de ar ventilada sobre segunda laje de concreto e, internamente, provida de rebaixo em gesso, que forma uma segunda câmara de ar, esta não ventilada.

A cobertura sobre parte central do prédio, que abriga a área de exposições e recepção, é provida de isolamento térmico sobre laje de concreto e rebaixo em gesso internamente. Por fim, a cobertura do bloco onde se situa o auditório é naturada, o que garante bom isolamento térmico, reduzindo os ganhos de calor no interior, inclusive pelo incremento da perda de calor pela cobertura pela evapotranspiração das plantas. Desse modo, as características das coberturas possibilitaram o cumprimento do pré-requisito transmitância térmica das coberturas, comprovadas através dos cálculos realizados.

Para cálculo da transmitância das paredes, sua capacidade térmica foi ponderada, uma vez que são compostas de diversos materiais, assim como suas transmitâncias, obtendo-se um valor final enquadrado nos limites permitidos para essa zona bioclimática.

As absortâncias, diretamente dependentes das cores das coberturas e das paredes, foram também ponderadas por suas áreas e, desde que as coberturas (exceto a naturada) sejam pintadas com cores claras (o que não é definido em projeto), estarão dentro dos valores permitidos para a zona bioclimática em questão.

Por fim, uma vez que o percentual de abertura zenital é baixo, com o valor de $0,07 \%$, a envoltória poderá manter sua classificação $\mathrm{A}$, desde que o fator solar máximo do elemento transparente das aberturas zenitais localizadas nos banheiros seja 0,87, o que é atendido com a utilização de vidro comum. Porém, vale reforçar que a utilização de vidros com tão pouca espessura não é indicada.

O Quadro 1 apresenta os valores dos pré-requisitos atendidos pelo projeto.

\section{Bonificações}

Quanto às bonificações, o RTQ-C (BRASIL, 2009c) define que:

(a) sistemas que racionalizem o uso da água devem proporcionar economia mínima de $20 \%$ no consumo anual, o que equivale a um ponto de bonificação; e

(b) energia eólica ou painéis fotovoltaicos devem proporcionar economia mínima de $10 \%$ no consumo anual de energia.

O prédio prevê a instalação de painéis fotovoltaicos, uso de energia eólica e captação de águas pluviais, o que confere pontos de bonificação. 


\begin{tabular}{l|c|c|c|c|c}
\hline Eficiência & A & B & C & D & E \\
\hline Lim mín & - & 462,23 & 466,38 & 470,52 & 474,67 \\
\hline Lim máx & 462,22 & 466,37 & 470,51 & 474,66 & - \\
\hline
\end{tabular}

Tabela 6 - Limites dos intervalos dos níveis de eficiência do edifício analisado

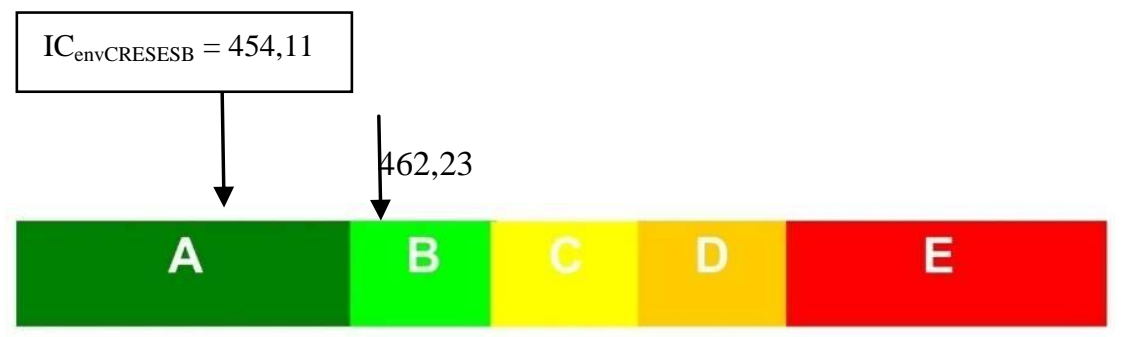

Fonte: Brasil (2009b).

Figura 14 - Indicação do nível A de eficiência energética da envoltória

\begin{tabular}{|c|c|c|c|}
\hline Nível & $\begin{array}{c}\text { Transmitância térmica da } \\
\text { cobertura e paredes exteriores }\end{array}$ & Cores e absortância de superfícies & $\begin{array}{l}\text { Iluminação } \\
\text { zenital }\end{array}$ \\
\hline A & $\begin{array}{l}\text { Ucobmáx }=0,86 \mathrm{~W} / \mathrm{m}^{2} \mathrm{~K} \\
<\text { Ucobmáx permitido }\left(1,0 \mathrm{~W} / \mathrm{m}^{2} \mathrm{~K}\right. \\
\text { para condicionadas e } 2,0 \mathrm{~W} / \mathrm{m}^{2} \mathrm{~K} \\
\text { para não condicionadas }) \\
\text { Upar }=2,3 \mathrm{~W} / \mathrm{m}^{2} \mathrm{~K} \\
<\text { Uparmáx }\left(3,7 \mathrm{~W} / \mathrm{m}^{2} \mathrm{~K} \text { para }\right. \\
\mathrm{ZB} 8 \text { com capacidade térmica }>80 \\
\mathrm{~kJ} / \mathrm{m}^{2} \mathrm{~K}\end{array}$ & $\begin{array}{l}\text { Coberturas: } \\
\text { Para ZB8, } \alpha_{\text {máxcoberturanãoaparentes }}=0,4 \\
\text { OBS.: para cumprir este pré- } \\
\text { requisito, as superfícies (exceto a } \\
\text { cobertura verde) devem ter cores } \\
\text { claras } \\
\underline{\alpha_{\text {parede }}}=0,2 \\
<\alpha_{\text {máxparedes }}(0,4 \text { para ZB8) }\end{array}$ & $\begin{array}{l}\mathrm{PAZ}=0,07 \% \\
\text { OBS.: para } \\
\text { cumprir este } \\
\text { pré-requisito, o } \\
\text { FS máximo } \\
\text { deve ser } 0,87\end{array}$ \\
\hline
\end{tabular}

Quadro 1 - Pré-requisitos específicos da envoltória

De acordo com Lomardo et al. (2007a), a simulação realizada com o software VisualDOE comprovou que a fração solar (que corresponde à fração do consumo coberta pela geração solar) da geração de energia com os painéis fotovoltaicos corresponde a aproximadamente $21 \%$ do consumo anual previsto para a edificação. A geração de energia eólica pode ser considerada irrisória para o prédio (sua fração corresponde a cerca de $0,2 \%$ ), mas os $21 \%$ correspondentes à energia fotovoltaica garantem ao edifício o ponto de bonificação.

O uso de aparelhos eficientes (bacia de dois fluxos e arejadores) permitirá uma economia de $38 \%$ no consumo de água, o que ultrapassa a economia mínima de $20 \%$ para a bonificação de racionamento de uso de água.

\section{Classificação final}

Após a avaliação dos sistemas de iluminação e condicionamento artificiais e somado o ponto de bonificação, o projeto do edifício atingiu nível A de eficiência energética, conforme demonstrado na equação a seguir:
$\mathrm{PT}=0,3 \times\{($ EqNumEnv $\mathrm{x}$ AC/AU $)+($ APT/AU $\mathrm{x}$ $5+$ ANC/AU $x$ EqNumV $)\}+(0,3 \times$ EqNumDPI $)$ $+0,4 \times\{($ EqNumCA $\times$ AC/AU $)+($ APT/AU $\times 5+$ ANC/AU $x$ EqNumV) $\}+b_{0}{ }^{1}=5,326$

Onde:

EqNumEnv $=5$

EqNumDPI $=2,75$

$\mathrm{EqNumCA}=5$

$\mathrm{AU}\left(\mathrm{m}^{2}\right)=310,39$

$\mathrm{AC}\left(\mathrm{m}^{2}\right)=301,18$

$\operatorname{ANC}\left(\mathrm{m}^{2}\right)=0$

$\operatorname{APT}\left(m^{2}\right)=9,21$

$\mathrm{b}_{0}{ }^{1}=1,0$

Os pré-requisitos gerais exigem:

(a) circuito elétrico com possibilidade de medição centralizada por uso final (iluminação, sistema de condicionamento de ar e outros);

(b) uso de sistema eficiente para aquecimento de água, caso haja demanda;

(c) bombas de água centrífugas etiquetadas pelo Inmetro; e 
(d) controle inteligente de tráfego. No caso desse edifício, apenas o pré-requisito de bombas etiquetadas deverá ser atendido e especificado em projeto, uma vez que o prédio não apresenta demanda para aquecimento de água nem de elevadores.

\section{Conclusões}

A avaliação A de eficiência energética para este projeto avaliza que foi alcançado o principal objetivo do Centro de Informações do Cresesb, qual seja, difundir o uso de tecnologias energeticamente eficientes, notadamente a solar e a eólica, além de demonstrar como construir aproveitando os recursos naturais disponíveis. $\mathrm{O}$ efeito multiplicador da exposição pública de técnicas replicáveis em residências, escolas, unidades comerciais e industriais é de difícil mensuração, mas de grande valor para a sociedade.

Algumas tecnologias aplicadas no Centro já são financeiramente viáveis, outras, como a energia fotovoltaicas, só o serão em um futuro próximo, dados os custos crescentes dos recursos ambientais ou quando avaliados os benefícios sociais.

O estudo de conforto ambiental e eficiência energética do projeto comprovou a eficiência de um bom projeto de arquitetura, que, mesmo com restrições orçamentárias, alcançou um excelente resultado plástico e levou em conta as características climáticas locais, constituindo um exemplo de arquitetura bioclimática.

Decisões de arquitetura em fases iniciais de projeto, como implantação, uso de áticos ventilados, instalação de elementos de sombreamento nas fachadas, poucas aberturas na fachada oeste, grandes envidraçados com controle do ganho térmico, cores claras nas fachadas e coberturas, cobertura naturada e materiais de construção que proporcionem baixa transmitância térmica, somadas ao bom projeto de aberturas que proporcionem ventilação cruzada interior, são alguns dos recursos que põem em prática as recomendações de Givoni (1992) e Lippsmeier (1980) para o clima tropical quente e úmido do Rio de Janeiro e que garantem a eficiência energética de um projeto de arquitetura.

Somados a tais decisões, a previsão de instalação de painéis solares, o uso racional de água e a captação de água da chuva para reúso em irrigação agregam medidas que enfatizam que a sustentabilidade pode ser um diferenciador na qualidade final do produto arquitetônico.

Com a aplicação do RTQ-C (BRASIL, 2009c), constatou-se a importância da especificação em projeto de pequenos detalhes e quesitos que devem ser atendidos e que, por isso, devem fazer parte das especificações a partir de então, como definição de cores claras para a envoltória e indicação de fator solar baixo para grandes áreas envidraçadas, especificações relevantes para garantir os níveis máximos de eficiência.

Observamos que os equipamentos de ar condicionado e de iluminação mudam de classificação de eficiência energética periodicamente, pois os parâmetros das avaliações do PBE/Inmetro sofrem revisões. Assim, é de fundamental importância que as especificações de projetos para licitações públicas de edifícios exijam como pré-requisito itens avaliados como A. Dessa forma, esses projetos manterão a mesma qualidade, mesmo que a dinâmica da avaliação desses equipamentos se altere.

Por fim, é essencial que sejam atendidas outras resoluções que se somam às avaliadas pelo RTQ-C (BRASIL, 2009c), visando ajustar o projeto às normas técnicas relativas aos projetos de ar condicionado (NBR 16401 (ABNT, 2008)), à portaria $n^{0} 3.523 / G M$ do Ministério da Saúde e à Resolução $n^{\circ} 9$ da ANVISA, como a renovação mínima de ar e o consequente aumento de consumo de energia (FONSECA et al., 2009).

\section{Referências}

AGÊNCIA NACIONAL DE ÁGUAS (ANA); FEDERAÇÃO DAS INDÚSTRIAS DO ESTADO DE SÃO PAULO (FIESP). Conservação e Reúso da Água em Edificações. São Paulo, 2005.

\section{ASSOCIAÇÃO BRASILEIRA DE NORMAS} TÉCNICAS. NBR 16401-1: instalações de arcondicionado: sistemas centrais e unitários: parte 1: Projetos das instalações. Rio de Janeiro, 2008.

\section{ASSOCIAÇÃO BRASILEIRA DE NORMAS}

TÉCNICAS. NBR 15220-3: desempenho térmico de edificações: parte 3: zoneamento bioclimático brasileiro e diretrizes construtivas para habitações unifamiliares de interesse social. Rio de Janeiro, 2005.

BARROSO-KRAUSE, C. et al. Bioclimatismo no Projeto de Arquitetura: dicas de projeto. Rio de Janeiro: FAU-UFRJ, 2005.

BRASIL. Empresa de Pesquisa Energética (EPE). Balanço Energético 2006: ano base 2005. Rio de Janeiro, 2006. 
BRASIL. Instituto Nacional de Meteorologia. Normais Climatológicas. Brasília, DF, 2010. Disponível em:

<http://www.inmet.gov.br/html/clima/graficos/plot Graf.php?chklist=2\%2C\&capita=riodejaneiro $\% 2 \mathrm{C}$ \&peri $=99 \% 2$ C\&per6190 $=99 \&$ precipitacao $=2 \&$ rio dejaneiro $=34 \&$ Enviar $=$ Visualizar $>$. Acesso em: 09 jun. 2010.

BRASIL. Instituto Nacional de Metrologia, Normalização e Qualidade Industrial (INMETRO). Etiquetagem de Eficiência Energética de Edificações. Rio de Janeiro, 2009a. v. 1.

BRASIL. Instituto Nacional de Metrologia, Normalização e Qualidade Industrial (INMETRO). Manual para Aplicação dos Regulamentos: RTQ-C e RAC-C. Rio de Janeiro, 2009b. v. 4.

BRASIL. Regulamento Técnico da Qualidade do Nível de Eficiência Energética de Edifícios Comerciais, de Serviços e Públicos. Rio de Janeiro, 2009c. v. 2.

FONSECA, I. et al. Pesquisas para Conservação de Energia Elétrica: aplicação do Regulamento Técnico da Qualidade do Nível de Eficiência Energética de Edifícios Comerciais, de Serviços e Públicos no prédio do CRESESB. Rio de Janeiro: LABCECA/UFF: Eletrobrás, 2009. Relatório científico, convênio Eletrobrás n. ECV280/2008.

GALDINO, M. A. et al. Implantação do Centro de Informações do CRESESB. In: CONGRESSO BRASILEIRO DE ENERGIA SOLAR, 1., 2007, Fortaleza. Anais... Fortaleza: Associação Brasileira de Energia Solar, 2007.

GIVONI, B. Comfort, Climate Analysis and Building Design Guidelines. Energy and Buildings, Lausanne, v. 18, p. 11-23, July 1992.

GOULART, S.; LAMBERTS, R.; FIRMINO, S. Dados Climáticos para Projetos e Avaliação Energética de Edificações para 14 Cidades Brasileiras. 2. ed. Florianópolis: Procel, 1998.

LAMBERTS, R.; DUTRA, L.; PEREIRA, F. O. R. Eficiência Energética na Arquitetura. São Paulo: PW, 1997.

LIPPSMEIER, G. Tropenbau: building in the tropics. München: Callwey Verlag, 1980.

LOMARDO, L. et al. Análise Energética do Prédio do Centro de Informações do CRESESB. In: SEMINÁRIO NACIONAL DE PRODUÇÃO E TRANSMISSÃO DE ENERGIA ELÉTRICA, 19., 2007, Rio de Janeiro. Anais... Rio de Janeiro: Cigré-Brasil, 2007a.
LOMARDO, L. et al. Memorial justificativo do Prêmio PROCEL 2007: projeto do CRESESB. Rio de Janeiro: Brochura, 2007b.

MACIEL, A. A. et al. Projeto Casa Eficiente: demonstração de eficiência energética em habitação unifamiliar. In: ENCONTRO NACIONAL EM TECNOLOGIA DO AMBIENTE CONSTRUÍDO, 6. 2006, Florianópolis. Anais... Porto Alegre: ANTAC, 2006. p. 3392-3401.

MELLO, E. N. Desempenho Térmico de Blocos para Vedação: avaliação comparativa de célulasteste em Niterói - RJ. 2006. 220 f. Dissertação (Mestrado em Arquitetura e Urbanismo) Universidade Federal Fluminense, Niterói, 2006.

PACIFIC GAS AND ELECTRIC COMPANY (PG\&E). Resource Center. San Francisco, c2009. Disponível em:

<http://www.pge.com/mybusiness/edusafety/traini ng/pec/tour/basement.shtml >. Acesso em: 28 maio 2010.

SILVA FILHO, V. P. Simulação Computacional do Projeto Centro de Informação CRESESB: avaliação do desempenho termoenergético e da relação custo $\mathrm{X}$ benefício do elemento cobertura. Dissertação (Mestrado em Arquitetura e Urbanismo) - Universidade Federal Fluminense, Niterói, 2007.

\section{Agradecimentos}

À Eletrobrás, que vem apoiando o Laboratório de Conservação de Energia e Conforto Ambiental (LabCECA).

Ao $\mathrm{CNPq}$, que igualmente vem apoiando o LabCECA.

Aos bolsistas de iniciação científica que colaboraram na aplicação do RTQ-C, Tom Caminha e Igor Soares.

Ao engenheiro mecânico Jairo Francisco R. P. de Souza, autor do projeto de ar condicionado do Cresesb, além de consultor na aplicação do RTQ$\mathrm{C}$, e ao engenheiro Vitor Carneiro, pelos cálculos financeiros. 